\title{
LA IGLESIA CATÓLICA Y LOS ENCUENTROS NACIONALES DE MUJERES
}

\author{
MÓNICA TARDUCCI
}

Universidad de Buenós Aires

\begin{abstract}
Resumen: La enorme influencia que tiene la Iglesia Católica en Argentina se pone de manifiesto de manera dramática cada vez que se intentan cambios legislativos que avancen en favor de los derechos humanos en general y de las mujeres en particular. Su tenaz oposición a la Ley Nacional de Salud Reproductiva, asi como a la Unión Civil o la Educación Sexual en las escuelas (estas últimas en el ámbito acotado de la ciudad de Buenos Aires), son algunos de los ejemplos más recientes. En tal situación, los Encuentros Nacionales de Mujeres se están transformando en el escenario de virulentas confrontaciones entre las mujeres enviadas por las paroquias con instrucciones precisas de imponer una visión fundamentalista en determinados temas y la inmensa mayoría de las participantes que, católicas o no, intentan debatir las prioridades del movimiento amplio de mujeres de Argentina.
\end{abstract}

Palabras claves: Iglesia Católica, movimiento de mujeres, feminismo, derechos sexuales y reproductivos.

Desde 1986, todos los años se realizan en diferentes ciudades de Argentina, los Encuentros Nacionales de Mujeres. El primero de ellos, en la ciudad de Buenos Aires, fue iniciativa de un grupo de feministas. Hoy decimos que las feministas militantes somos la minoría ya que la cantidad de mujeres creció de tal manera, que en los últimos, se superó la cifra de doce mil asistentes.

Desde un comienzo humilde (no eramos mas de mil) se ha llegado a un evento no sólo multitudinario sino multifacético, donde se pueden encontrar mujeres universitarias, activistas de Derechos Humanos, sindicalistas, estudiantes, feministas, de partidos políticos (en especial de izquierda y progresistas) y podemos afirmar que la gran mayoria de las asistentes son mujeres de sectores populares, que llegan organizadas en partidos políticos, movimientos de desocupados/as, comedores comunitarios, etc. Para muchas de ellas es una experiencia única y tan valiosa que suelen hablar de "un antes y despues de su primer encuentro".

Copyright $\odot 2005$ by Revista Estudos Feministas 
Los Encuentros están organizados por una comisión ad hoc compuesta por mujeres de la ciudad donde se realiza, que es la encargada de concretar y facilitar estos eventos que duran tres días (sábado, domingo y un lunes no laborable) y se llevan a cabo en escuelas y universidades públicas.

Los Encuentros se organizan en talleres temáticos que cada año se abren a problemáticas muy diversas. A los tradicionales como Salud, Trabajo, Violencia, Sexualidad, Derechos Humanos, etc, se le fue sumando no sólo un mayor nivel de especificidad temática, como "Salud Mental", "Ligadura de trompas", "Lesbianismo", sino que también se incorporan áreas antes no tenidas en cuenta como "Mujeres de los pueblos originarios", "Mujeres migrantes", "Ecología y Medioambiente", "Adicciones", "Ciencia y Tecnología", "Deuda Externa y ALCA". Sucede también que algunos sean coyunturales o surgidos de una urgencia, como lo fue en el 2003 el de "Las mujeres ante las catástrofes y crisis evitables", coordinado por mujeres de la ciudad de Santa Fe, que aún padecen las terribles consecuencias de las inundaciones sufridas ese año.

Tanto la elección como la permanencia dentro de los talleres es voluntaria. De común acuerdo, se establece un límite a la cantidad de participantes por taller y cuando se supera ese número, se abre otro con la misma temática. Cada grupo tiene una coordinadora y asistentes que toman nota del debate y elaboran las conclusiones y propuestas de acción consensuadas.

Mas allá de las intensas y muchas veces conflictivas discusiones en los talleres, los Encuentros son espacios donde las mujeres comparten experiencias, conocen lugares nuevos, adquieren publicaciones específicas, forman redes de información, llevan a vender sus artesanías, y como muchas de ellas lo expresan orgullosas "aprenden a hablar en público".

Quienes concurrimos habitualmente, estabamos acostumbradas a lidiar con compañeras militantes de partidos políticos de izquierda, que disputan un terreno codiciado dada la masiva presencia de mujeres. Estos partidos no sólo compiten en facilitar la concurrencia de mujeres de sectores populares sino también en introducir los temas de sus agendas políticas del momento. ' A lo que no estábamos acostumbradas es a la presencia en los mismos talleres, de mujeres pertenecientes de manera orgánica a la Iglesia Católica, que desembarcaron disciplinadamente con consignas claras y órdenes precisas.

\section{El desembarco}

En 1997 el Encuentro Nacional de Mujeres tuvo lugar en la ciudad de San Juan, capital de la provincia de igual nombre. La Iglesia Católica local organizó un evento paralelo y se dedicó a hostigar a las mujeres que participaron del Encuentro. Pero fue en Salta, (una provincia conservadora del noroeste del país) en el año 2002, donde se pudo ver a mujeres católicas, coordinadas y dispuestas a imponer las directivas del Vaticano en los talleres. Ellas mismas reconocieron que éste habia sido un encuentro "distinto" y un punto de inflexión en la historia de los Encuentros. Con esos antecedentes no se esperaba algo mejor para el siguiente, que se realizaría en la ciudad de Rosario. Pero lo realmente sorprendente fue la filtración de una carta enviada por la arquidiócesis de Rosario a todas las parroquias de su distrito, en la que se lee:

\footnotetext{
' Respecto a visiones críticas de los Encuentros desde el feminismo autónomo ver Magui BELLOTI, 2002; e Alejandra CIRIZA, 2004a e 2004b.
} 


\section{Estimado Padre:}

Los días 16, 17 y 18 de Agosto tendrá lugar en Rosario, el XVIII Encuentro Nacional de Mujeres Autoconvocadas. En el mismo se busca reunir a numerosas mujeres del país (en algunos asistieron más de 12.000), para que defiendan la problemática de la mujer en la sociedad con una mirada parcializada sobre la dignidad de la mujer y sus derechos.

El encuentro está organizado en talleres (por Ej.: mujer y cárcel, mujer y adolescencia, mujer y deuda externa, mujer y tercera edad, mujer y educación, mujer y partidos políticos, mujer y sindicato, etc.) pero, en realidad, todos tienen temas transversales de fondo, tales como el feminismo de género, el aborto, el lesbianismo, la anticoncepción, la desvalorización de la familia tradicional y de la maternidad. Al concluir el trabajo, las conclusiones son enviadas a políticos y legisladores para urgir la elaboración e implementación de leyes.

Considerando esto y viendo la necesidad que las mujeres católicas participemos en dicho encuentro, Mons. Eduardo V. Mirás, decidió formar en diciembre del año pasado, una Comisión de Mujeres que tiene a su cargo la motivación y preparación de las participantes. Es por eso que le pedimos tenga a bien invitar al menos 10 mujeres de su comunidad, que fieles a su bautismo y con profundo amor a la Iglesia, se sientan movidas a intervenir en dicho encuentro para testimoniar la defensa de los derechos de la mujer y de la vida desde una perspectiva cristiana .

Dado que este evento no es una instancia de formación sino de confrontación donde deben quedar claros y bien fundamentados los principios de orden natural que dignifican a la mujer, será necesario enviar mujeres con cierta formación en el tema del taller que elijan para participar.

Le adjuntamos la ficha de identificación para cada mujer convocada y que decida participar.

A la espera de su atenta respuesta, lo saludamos fraternalmente en Cristo y su Santísima Madre.

(la carta continuaba con el listado completo de los talleres, para que las mujeres se anotaran)

Con semejante amenaza, el movimiento de mujeres y especialmente las femenistas fuimos un poco mas organizadas y sabiendo lo que nos esperaba. Incluso se rechazó explicitamente "la políica de confrontación", sobre la que alertaba el arzobispo de Rosario, lamentado que la "Iglesia Católica quiera conservar el tutelaje sobre las mujeres, impidiendo y queriendo controlar los espacios libres, autónomos y horizontales que hemos creado para reflexionar, debatir, intercambiar experiencias y definir acciones conjuntas", como lo expresó el comunicado del movimiento de mujeres de Cordoba.

A diferencia de Salta, Rosario es una ciudad mas cosmopolita, con una gestión progresista (del Partido Socialista) que facilitó la participación en el Encuentro con becas y otros tipos de ayuda. Como comentamos en otro trabajo ${ }^{3}$ las mujeres enviadas por las parroquias no sólo estaban en los talleres sobre aborto o salud reproductiva, sus espacios "clásicos", sino que su presencia, además de numerosa, fue notable en gran cantidad de talleres. Quedaba muy claro en su discurso, cualquiera sea la temática abordada, cuales eran las consignas que debían bajar: "derecho a la vida desde la concepción", no al uso del condón, no al anticonceptivo de emergencia, la insistencia en que las políticas de población son una imposición imperialista hacia los países pobres, no al concepto de género, defensa de la familia (heterosexual), dignificación del trabajo doméstico, no al lesbianismo y la homosexualidad. Aunque no identificaban su pertenencia, como suelen

${ }^{2}$ Carta de la "Comisión Arquidiocesana para el XVIII Encuentro Nacional de Mujeres", 8 de marzo de 2003.

${ }^{3}$ Mónica TARDUCCI y Barbara TAGLIAFERRO, 2004. 
hacer las mujeres en los talleres, el discurso monolítico, el autoritarismo, etnocentrismo y racismo, las identificaba rapidamente.

Las jornadas fueron agotadoras, discusiones imposibles entre el dogma y la razón, entre los ideales de emancipación humana y la imposibilidad de comprender la diversidad ni el derecho humano a la libertad de decidir. Se creó de hecho un "nosostras" y "ellas" que polarizó totalmente el encuentro y nos hizo olvidar nuestras rencillas internas. ${ }^{4}$

Por otro lado colocó en el centro del debate al aborto, logrando que la prensa oral y escrita hablara del Encuentro sólo para referirse a las virulentas discusiones en torno al tema.

Como es costumbre en todos los Encuentros, se realizó una marcha por la ciudad, que fue una de las mas alegres, multitudinarias y coloridas que yo recuerde. Especialmente colorida porque la organización Católicas por el Derecho a Decidir de la ciudad de Córdoba, había llevado al Encuentro pañuelos verdes con inscripciones tales como "Católicas por los anticonceptivos", "Por la depenalización del aborto", "Por la anticoncepción", que fueron distribuídos al comenzar la marcha. Este hecho tuvo gran impacto visual ya que si lo llevabas puesto significaba estar a favor de la libre elección y fundamentalmente no eras parte de "ellas". La marcha por la ciudad, tal como lo mostraron las fotografías de los diarios nacionales fue ampliamente "verde", además de anti-clerical en las consignas ya clásicas contra una Iglesia Católica que no sólo se opone a nuestros derechos sino que fue cómplice de la dictadura militar.

\section{Paso a la accion directa}

Llegamos al 2004 sabiendo que Mendoza, la ciudad elegida para que entre el 9 y el 11 de octubre se llevara a cabo el XIX Encuentro Nacional de Mujeres, sería hostil por su conservadurismo. Además se había hecho público a mediados de año el documento vaticano "Carta a los obispos de la Iglesia Católica sobre la colaboración del hombre y la mujer en la iglesia y el mundo", verdadera declaración antifeminista, que no hacía mas que poner por escrito lo que a diario se escucha desde los órganos de difusión eclesiales.

Sabíamos también de las dificultades que tenían las feministas que eran parte de la organización de un encuentro donde ellas eran minoría. Por lo tanto hubo, en distintas regiones del país reuniones previas para llevar a Mendoza acciones concretas ante una oposición que iba a ser feroz. También la Iglesia se había organizado, incluso llevando el tema a las escuelas religiosas para repudiar el evento.

Apenas arrivadas vimos la cantidad de afiches con que se había empapelado la ciudad. En ellos, imágenes de niños y bebes acompañaban consignas tales como "No le des la espalda", "Elige la vida", "Mendoza por la vida". Quedamos azoradas cuando vimos las paredes de las escuelas donde transcurrirían los talleres con graffitis que decían "No a las autoconvocadas", "Asesinas", "No al aborto", "No a la Plaza de Mayo", "No a la educación sexual".

A la presencia masiva de mujeres enviadas por la Iglesia, en Mendoza se le sumó la agresión verbal y física: asistentes que fueron golpeadas en la calle, se rompieron los vidrios en una escuela donde dormían quienes no podían pagar un hotel, hubo actos de sabotaje contra los buses que habian llevado a las mujeres al Encuentro, etc. Dos hechos fueron especialmente graves y concitaron la atención de la prensa: la bomba que incendió la instalación eléctrica del club donde se iba a realizar el baile y la quema de folletos del

${ }^{4}$ Muchas compañeras católicas protestaban por ese apelativo. Entonces para distinguir a las católicas "buenas" de las "malas", comenzamos a designar a las enviadas por las parroquias como "catequistas". 
Programa Provincial de Salud Reproductiva en el anfiteatro (de madera) de la escuela donde se llevaban a cabo la mayor parte de los talleres.

Demás esta decir el clima de tensión que se vivió en esos tres días. La guerra declarada del año anterior con el agravante de las agresiones físicas, calumnias a la prensa, intromisión de hombres hostiles en las escuelas donde se llevaron a cabo los talleres....y la marcha. En ella, una tradición del última dia de los Encuentros, las aproximadamente doce mil mujeres, (según la prensa quince mil) otra vez con los pañuelos verdes de las Católicas por el Derecho a Decidir ${ }^{5}$, desfilaron por la ciudad, con consignas muy claras sobre la libertad sexual y el derecho al aborto, sin olvidar las consignas referidas a la situación económica y por supuesto a la actitud colaboracionista de la iglesia durante la dictadura.

Pero Mendoza no dejaba de sorprendernos en su conservadurismo católico: en un momento en que las mujeres ( $y$ algunos hombres) pasabamos frente a una iglesia miramos estupefactas como una guardia conformada por un hombre al lado de otro, custodiaban el templo, con los brazos en alto, al grito de "Vida!", "Viva Cristo Rey", "Viva la Virgen", "Viva el papa".

\section{Discusión}

Cuando las feministas analizamos el XVIII Encuentro Nacional de Mujeres (2003, Rosario) estabamos optimistas porque la ofensiva de la Iglesia Católica había tenido resultados no deseados por ésta, como lo fue que miles de mujeres se unieran en la exigencia de políticas públicas referidas a la anticoncepción y el aborto. La habíamos desafiado en lo que hoy es su mayor preocupación: la sexualidad y los derechos reproductivos.

Después de Mendoza, y a pesar de las miles de mujeres en la calle y de la repercusión en los medios masivos de comunicación algunas feministas, entre las que me incluyo, estamos preocupadas.

Preocupadas porque una confrontación tan violenta polariza posiciones y no permite discutir seriamente los problemas que nos interesan como mujeres. Que todo el mundo hable del "encuentro del aborto", pone el tema en la agenda y eso está muy bien, pero en Mendoza hubo 50 talleres diferentes y sólo algunos trataron temas relacionados con los derechos reproductivos.

El mismo tema del aborto se transforma en una discusión sin matices, donde lo único que importa es rebatir a las católicas, discusión absurda porque contra el dogma no se puede razonar. No se comparten las experiencias de las mujeres ni se puede pensar con tranquilidad los pasos a seguir en un país donde ni siquiera se ha firmado la Convención para la Eliminación de Todas las Formas de Discriminación contra la Mujer (CEDAW), se obstaculiza la implementación de la ley Nacional de Salud Reproductiva y la Educación Sexual en las escuelas, entre otras cosas, por la oposición de la Iglesia Católica.

La dinámica de los talleres se ve alterada además, porque se tiene que recurrir al voto para dirimir las diferentes posiciones, pervirtiendo los objetivos de los Encuentros. Y ¿qué sucede con las mujeres que se acercan por primera vez, a lo que se ha convertido en una guerra para expertas? No tenemos ni tiempo para compartir con ellas porque todo nuestro esfuerzo está puesto en defendernos de la agresión papista.

${ }^{5}$ El impacto de los pañuelos fue tal que el diario Pagina 12, en su edición del 11 de octubre de 2004, día de cierre del XIX Encuentro, tituló su nota central de dos páginas "Igual, los pañuelos verdes marcharon". 
Las feministas no vamos a los Encuentros a disputar el poder de éstos. Vamos con nuestras consignas, con nuestras ideas emancipatorias, con nuestra creatividad, con ganas de hacer política y de gozar el hecho de estar entre mujeres. Cómo hacerlo si pareciera que lo único posible es la urgencia de la confrontación, de una disputa que no buscamos. ${ }^{6}$

Cómo seguirán los Encuentros, habida cuenta de lo sucedido en los dos últimos? Las perspectivas no son optimistas:

Volverán (las católicas), como me dijo una de ellas en la Escuela de la que yo estaba encargada. Volverán dentro de un año, cuando nosotras, una vez más organicemos un Encuentro, esta vez en Mar del Plata. Volverán, apelando a su condición de mujeres, usando como argumentos la democracia y la tolerancia que desprecian, medrando con nuestro trabajo, apostando a desgastarnos en interminables discusiones en las cuales desde luego, es imposible avanzar; continuarán violentándonos, agrediéndonos sin culpa: las tradiciones de misoginia y odio a la diferencia están allí para avalarlas/los.

\section{Referencias bibliográficas}

BELLOTTI, Magui. “17 Encuentro Nacional de Mujeres: Lo personal es político”. Brujas, v. 21, n. 29, p. 42-55, 2002.

CIRIZA, Alejandra. "Mendoza, escenario del XIX Encuentro Nacional de Mujeres". Rima (Red Informativa de Mujeres Argentinas). 22 oct. 2004a. Documento de la Web: www.rimaweb.com.ar.

CIRIZA, Alejandra. "Voces feministas fuera de lugar. Sobre los Encuentros Nacionales de Mujeres vistos desde la perisferia". Brujas, v. 22, n. 30, p. 26-35, 2004b.

TARDUCCI, Mónica; TAGLIAFERRO, Barbara. "Iglesia Católica: Argentina ni diversa ni laica". Política y Cultura, n. 21, p.191-200, 2004.

\section{Catholic Church and the "Encuentros Nacionales de Mujeres"}

Abstract: The power that Catholic Church has in Argentina is dramatically demostrated when some laws about Human Rights, especially Women Rights, such as Ley Nacional de Salud Reproductiva, Educacion Sexual and others, are in the process of being approved. . In this context, the Women's Meetings (Encuentros Nacionales de Mujeres) are being converted into violent confrontations between Catholic women who are sent by their churches and a fundamentalist point of view against the majority of women (Catholic or otherwise) who try to debate the more important issues of the Women's Movement.

Key Words: Catholic Church-Women's Movement-Feminism-Sexual and Reproductive Rights.

' Para mencionar algo realmente placentero: en la inauguración del Encuentro, en la plaza mas importante de la ciudad, el grupo "Mujeres Públicas" realizó una creativa performance y durante la marcha se vió a la LesbianBand , una murga de feministas lesbianas.

${ }^{7}$ CIRIZA, 2004a. 